\title{
Quality management re-visited: a reflective review and agenda for future research
}

\author{
Rui Sousa ${ }^{\mathrm{a}, *}$, Christopher A. Voss ${ }^{\mathrm{b}, 1}$ \\ ${ }^{a}$ Faculdade de Economia e Gestão, Universidade Católica Portuguesa at Porto, Rua Diogo Botelho, 1327, 4169-005 Porto, Portugal \\ ${ }^{\mathrm{b}}$ London Business School, Sussex Place, Regent's Park, London NW1 4SA, UK
}

Keywords: Quality management; Literature review; Reflective

Quality management (QM) has become an all-pervasive management philosophy, finding its way into most sectors of today's business society. After the initial hype and enthusiasm, it is time to take stock of the knowledge accumulated in what is now a mature field of study and look for directions to take the field further forward. This article reflects on the mass of literature in the field, synthesizing, organizing and structuring knowledge and offering suggestions for future research. It reviews QM research organized along five main themes: the definition of QM, the definition of product quality, the impact of QM on firm performance, QM in the context of management theory and the implementation of QM. The article draws on these themes to reflect on three questions which are fundamental to re-visit and re-appraise QM: (i) What is QM? (ii) Is the set of practices associated with QM validas a whole? (iii) How to implement QM in a real business setting?

\section{Introduction}

Quality management (QM) was born almost two decades ago with the core ideas of W. Edwards Deming, Joseph Juran, Philip Crosby and Kaoru Ishikawa. Since then it has become an all-pervasive management philosophy finding its way into most sectors of today's business society. Many companies have now embedded QM practices into their normal operations and, more and more, these practices are being

\footnotetext{
* Corresponding author. Tel.: +351-22-6196200; fax: +351-22-6196291.

E-mail addresses: rsousa@porto.ucp.pt (R. Sousa), cvoss@london.edu (C.A. Voss).

${ }^{1}$ Tel.: +44-20-7262-5050; fax: +44-20-7724-7875.
}

stripped of their faddish connotations to the point that nowadays, it is generally accepted that QM is here to stay. After the initial hype and enthusiasm, it is time to take stock of the knowledge accumulated over the last two decades in what is now becoming a mature field of study and look for directions to take the field further forward.

A substantial literature review was published by Ahire et al. (1995). This was a mainly descriptive review, providing a thorough synthesis of articles published from 1970 to 1993 and categorizing the literature along the several components of QM. This review was a useful stepping-stone in helping to consolidate the field. As QM has now entered a mature phase (in terms of having established sound definitional and conceptual foundations), the objective of 
this paper is to re-visit it and provide a reflective review of its literature.

The paper looks at broad issues, rather than offering a systematic and descriptive coverage of the whole body of literature, as Ahire et al. (1995) did. Our aim is to synthesize, organize and structure knowledge from an academic/research standpoint and offer suggestions for future research. Despite our review having different objectives from Ahire et al. (1995), we focus on a similar literature scope. Namely, we mainly reflect on literature in the field of management, written in the context of QM, focusing on an integrated view of managing quality and maintaining a broader QM perspective. As such, we do not directly cover specific topics such as technical and analytical quality topics (e.g. quality control statistical techniques, cost models, etc.), discipline-specific articles (e.g. information systems, health care, etc.), literature specifically related to quality standards (e.g. ISO 9000) and quality awards (e.g. the European Foundation and Baldrige Quality Awards), and literature focusing on single individual components of QM (e.g. leadership, workforce management, supplier involvement, etc.). The focus of this paper is explicitly product quality. We have not addressed the area of service quality. The service literature has a strong focus on consumer perceptions and marketing area, e.g. SERVQUAL (Parasuraman et al., 1988), and is somewhat separate from the focus of this paper. A review of service quality has recently been published by Harvey (1998).

Within this remit, we classify the existing literature in five main research streams: the definition of QM, the definition of product quality, the impact of QM on firm performance, QM in the context of management theory and the implementation of QM. We review these five streams with the objective of reflecting on three questions that we consider fundamental in re-visiting and re-appraising QM.

The first question is existential and definitional in nature: Is there such a field as QM? If so, what does it consist of and how should we define its immediate output, "product quality"? The relevant research streams that we review are the definition of QM and the definition of product quality. Accepting that there is such a field as QM, the second fundamental question is whether the set of practices associated with $\mathrm{QM}$ is valid as a whole. In this connection, we review the research stream on the impact of QM on firm performance and how QM compares to existing management theory. Accepting the premise that QM is valid brings us to the third fundamental question: How to implement QM in a real business setting? In this connection, we review the research stream on the implementation of QM.

For each of the five research streams we synthesize the main findings and offer suggestions for future research. We conclude by re-visiting our three fundamental questions in the light of the literature review and provide overarching conclusions and general suggestions to take research in the QM field further forward.

\section{Defining quality management}

QM has been defined as a "philosophy or an approach to management" made up of a "set of mutually reinforcing principles, each of which is supported by a set of practices and techniques" (Dean and Bowen, 1994). As QM has become embedded in more and more organizations in the last two decades, it has come to mean different things to different people (Watson and Korukonda, 1995), to such an extent that it begs the question: Is there such a thing as QM? Hackman and Wageman (1995) answer this question affirmatively. They defend that QM exhibits convergent validity, since there is substantial agreement among the movement's founders about the key principles and practices of QM. Furthermore, they also attribute discriminant validity to $\mathrm{QM}$ arguing that, as espoused by the movement's founders, QM philosophy and practice can be reliably distinguished from other strategies for organizational improvement.

At the empirical level, the assessment of whether such a thing as QM exists and what constitutes QM should be made at the level of practices: practices are the observable facet of QM, and it is through them that managers work to realize organizational improvements. Principles are too general for empirical research and techniques are too detailed to obtain reliable results (e.g. one practice may be implemented via many optional techniques). For example, the QM principle continuous improvement can be supported by the practice "process management", which in turn can resort to several techniques such as statistical process control and Pareto analysis. 
Table 1

Comparison between five major instruments for measuring the degree of use of quality management practices

\begin{tabular}{|c|c|c|c|c|c|}
\hline & Flynn et al. (1995a) & Ahire et al. (1996) & Anderson et al. (1995) & Powell (1995) & Saraph et al. (1989) \\
\hline Main literature base & $\begin{array}{l}\text { Practitioner and empirical } \\
\text { literature which reports on } \\
\text { practices in actual use in the } \\
\text { US and Japan }\end{array}$ & $\begin{array}{l}\text { Literature on quality } \\
\text { management, organizational } \\
\text { behavior and general operations } \\
\text { management. Conceptual } \\
\text { literature and actual practices of } \\
\text { organizations as evidenced } \\
\text { through various case-studies and } \\
\text { empirical research }\end{array}$ & Deming's works & TQM literature & $\begin{array}{l}\text { Theoretical work of quality } \\
\text { gurus, including Deming, } \\
\text { Juran, Crosby and Ishikawa }\end{array}$ \\
\hline Survey sample & $\begin{array}{l}706 \text { respondents (plant } \\
\text { managers, supervisors, } \\
\text { workers) of } 42 \text { US } \\
\text { manufacturing firms ( }>100 \\
\text { employees) from the } \\
\text { machinery, electronics and } \\
\text { transportation components } \\
\text { industries }\end{array}$ & $\begin{array}{l}371 \text { US manufacturing plants } \\
\text { ( }>100 \text { employees); single } \\
\text { industry (motor vehicle parts } \\
\text { and accessories); single } \\
\text { respondent (plant manager) }\end{array}$ & $\begin{array}{l}41 \text { US manufacturing firms } \\
\text { ( }>100 \text { employees) from the } \\
\text { machinery, electronics and } \\
\text { transportation components } \\
\text { industries. Multiple } \\
\text { respondents (plant managers, } \\
\text { supervisors, workers) }\end{array}$ & $\begin{array}{l}54 \text { US manufacturing and } \\
\text { service firms ( }>50 \\
\text { employees); single } \\
\text { respondent (CEO or senior } \\
\text { quality manager) }\end{array}$ & $\begin{array}{l}162 \text { respondents (top quality } \\
\text { manager and/or general } \\
\text { manager) of } 89 \text { divisions of } \\
20 \text { US manufacturing and } \\
\text { service firms ( }>1000 \\
\text { employees); } 1 \text { or } 2 \\
\text { respondents per division }\end{array}$ \\
\hline Level of analysis & Plant & Plant & Plant & Business unit & Business unit \\
\hline \multicolumn{6}{|l|}{$\begin{array}{l}\text { Dimensions of quality } \\
\text { management practices }\end{array}$} \\
\hline \multirow[t]{4}{*}{ Infrastructure } & Top management support & Top management commitment & Visionary leadership & $\begin{array}{l}\text { Executive commitment } \\
\text { Adopting the philosophy }\end{array}$ & $\begin{array}{l}\text { The role of management } \\
\text { leadership and quality policy } \\
\text { The role of the quality } \\
\text { department }\end{array}$ \\
\hline & Customer relationship & Customer focus & & Closer to customers & \\
\hline & Supplier relationship & Supplier quality management & & Closer to suppliers & Supplier quality management \\
\hline & $\begin{array}{l}\text { Workforce management } \\
\text { Work attitudes }\end{array}$ & $\begin{array}{l}\text { Employee involvement } \\
\text { Employee empowerment } \\
\text { Employee training }\end{array}$ & $\begin{array}{l}\text { Internal co-operation } \\
\text { Employee fulfilment } \\
\text { Learning }\end{array}$ & $\begin{array}{l}\text { Training } \\
\text { Employee empowerment } \\
\text { Open organization }\end{array}$ & $\begin{array}{l}\text { Training } \\
\text { Employee relations }\end{array}$ \\
\hline \multirow[t]{2}{*}{ Core } & $\begin{array}{l}\text { Process flow management } \\
\text { SPC/feedback }\end{array}$ & $\begin{array}{l}\text { SPC usage } \\
\text { Internal quality information } \\
\text { usage }\end{array}$ & Process management & $\begin{array}{l}\text { Process improvement } \\
\text { Flexible manufacturing } \\
\text { Zero defects mentality } \\
\text { Measurement }\end{array}$ & $\begin{array}{l}\text { Process management } \\
\text { Quality data and reporting }\end{array}$ \\
\hline & Product design & $\begin{array}{l}\text { Design quality management } \\
\text { Benchmarking }\end{array}$ & & Benchmarking & Product/service design \\
\hline
\end{tabular}


Several studies have tried to synthesize the vast QM literature and identify the key QM practice dimensions. Associated instruments to measure these dimensions were developed and empirically tested via survey research. Table 1 compares five major studies and provides an approximate correspondence between the QM practice constructs that were identified. As shown in the table, there is substantial agreement as to the set of constructs classified under the QM umbrella. These constructs are all present in the frameworks used for the national quality awards, such as the Malcolm Baldrige National Quality Award in the US and the European Quality Award.

The agreement in the literature on what constitutes $\mathrm{QM}$ indicates that $\mathrm{QM}$ as a field has indeed matured and is laid down on solid definitional foundations. Despite this, future research should incrementally build on the already existing base. First, future studies should make explicit at what level they are addressing QM content: principles, practices or techniques. Some of the conflicting results reported in the literature may have to do with different levels of analysis of QM (e.g. while SPC - a technique supportive of the practice "process management"-may be observed as not being in use in a certain plant, other techniques supportive of the same practice, e.g. process data collection and analysis, may well be used instead, representing a good overall use of practice "process management"). Researchers should also strive for a standardization of definitional terms. For example, different terms have been used for "practices", such as "factors" (Saraph et al., 1989; Powell, 1995), "implementation constructs" (Ahire et al., 1996; Anderson et al., 1995) and "interventions" (Hackman and Wageman, 1995). Table 1 also demonstrates the profusion of different terms for what are essentially similar practices making up QM. Finally, there is the need to test the existing instruments to measure $\mathrm{QM}$ practice dimensions-typically developed using samples of large companies in well developed industry sectorsin still less well studied contexts, such as process industries, small volume production of customized products or industry sectors where creativity is key.

One dangerous trend that may threaten the soundness of the field's conceptual foundations is the inclusion by the practitioner community of an ever increasing range of practices under the QM umbrella in an attempt to re-package $\mathrm{QM}$ and make it more sellable after its initial hype. For example, the scope of the major quality awards assessment frameworks has been continuously enlarged making them overall "business excellence" models rather than strictly quality models. This trend carries with it the danger of destroying QM's convergent and discriminant validity, a challenge that the QM academic community will have to deal with in the future.

\section{Defining product quality}

Research in QM has been unable to arrive at a single definition of product quality. At best, several optional definitions were proposed. Garvin (1984) identified five major approaches to the definition of quality and the disciplines in which they are rooted (see Table 2). Reeves and Bednar (1994) identify similar definitional approaches to quality, and conclude that a global definition of quality does not exist; rather, different definitions of quality are appropriate under different circumstances.

Another important realization is that quality seems to be a multi-dimensional construct (Garvin, 1984; Hjorth-Anderson, 1984). Garvin (1984, 1987) proposed eight dimensions of product quality (performance, features, reliability, conformance, durability, serviceability, aesthetics and perceived quality) and

Table 2

Alternative approaches to the definition of product quality

\begin{tabular}{lll}
\hline Approach & Definitional variables & Underlying discipline \\
\hline Transcendent & Innate excellence & Philosophy \\
Product-based & Quantity of desired attributes & Economics \\
User-based & Satisfaction of individual consumer preferences & Economics, marketing and operations management \\
Manufacturing-based & Conformance to requirements & Operations management \\
Value-based & Affordable excellence & Operations management \\
\hline
\end{tabular}

Source: Garvin (1984). 
there is empirical evidence of the multi-dimensionality of the quality construct (Stone-Romero et al., 1997).

Despite the above findings, most research to date treats quality as an unidimensional construct and does not take the necessary care to state clearly the definition of quality used (Stone-Romero et al., 1997). In this connection, two main points should be considered in future research. First, future studies should use multi-dimensional measures of quality. The importance of recognizing the multi-dimensional nature of quality cannot be overstated. In fact, the relative strategic importance of the different quality dimensions varies across products and industries. An organization will only achieve competitive advantage through quality if there is a match between the importance that the markets assign to the individual quality dimensions and the organization's performance along those individual dimensions (Garvin, 1984). Also, different quality dimensions exhibit different relationships with other competitive variables such as cost and delivery dependability. For example, regarding cost, improved conformance quality may lead to reduced costs, while improvement in the performance dimension may imply reduced conformance and increased costs (Maani, 1989). In addition, the deficiencies of the existing QM literature in defining product quality have been identified as being responsible for conflicting results reported in the literature linking quality to outcomes such as market share, cost and profits (Reeves and Bednar, 1994). Finally, provision of different quality dimensions poses different demands on different organizational functions (e.g. marketing, design, manufacturing, purchasing) and may require different organizational practices (including QM practices) depending on the quality dimension in question (Flynn et al., 1995a). For example, while the design function and associated design practices are bound to influence most quality dimensions, the manufacturing function and practices will probably be limited to influencing conformance quality.

Second, future studies should not aim at a single definition of quality. Rather, they should focus upon the fundamental nature of an organization's output and use a definition of quality encompassing the relevant dimensions for that output. Garvin's $(1984,1987)$ eight quality dimensions are a robust framework for research, covering a wide range of products and markets, and thus, are a good starting point for choosing the right dimensions. However, in some cases, we may need to consider other quality dimensions, or aggregate/desegregate some of Garvin's basic dimensions to fit the particular situation being addressed. In this connection, there is the need to develop conceptual frameworks and measuring methods for specific contexts of the product quality construct (Reeves and Bednar, 1994).

\section{The impact of quality management on firm performance: the quality performance model}

One important area of research in QM has been the examination of the extent to which QM practices have an impact on firm performance. Fig. 1 depicts the model underlying this body of literature.

The quality performance model shows the several routes by which QM practice may impact on quality, operational and business performance. QM proponents argue that the set of QM practices reduce the manufacturing process variability (thus, increasing internal process quality and subsequently product conformance quality), e.g. by using statistical process control. Moreover, all other product quality dimensions will also be improved, e.g. by using design and customer minded QM practices. Garvin (1984) showed how, in turn, internal process quality and product quality performance could impact on operational and business performance. He proposed two main routes for the effect of quality on business performance: the manufacturing route and the market route (Fig. 1).

In the manufacturing route, improved internal process quality, meaning fewer defects, scrap and rework, results in improved operational performance (e.g. lower manufacturing costs, more dependable processes), and subsequent improvement in terms of manufacturing related order-winners and qualifiers. These in turn lead to improved business performance.

In the market route, improvements in product quality lead to increased sales and larger market shares, or alternatively, less elastic demand and higher prices. If the cost of achieving these gains is outweighed by the increases in contribution received by the firm, higher profits will result. Larger market shares can improve business performance directly and can also lead to indirect experience based cost savings and further gains in profitability. Less elastic demand and higher prices 


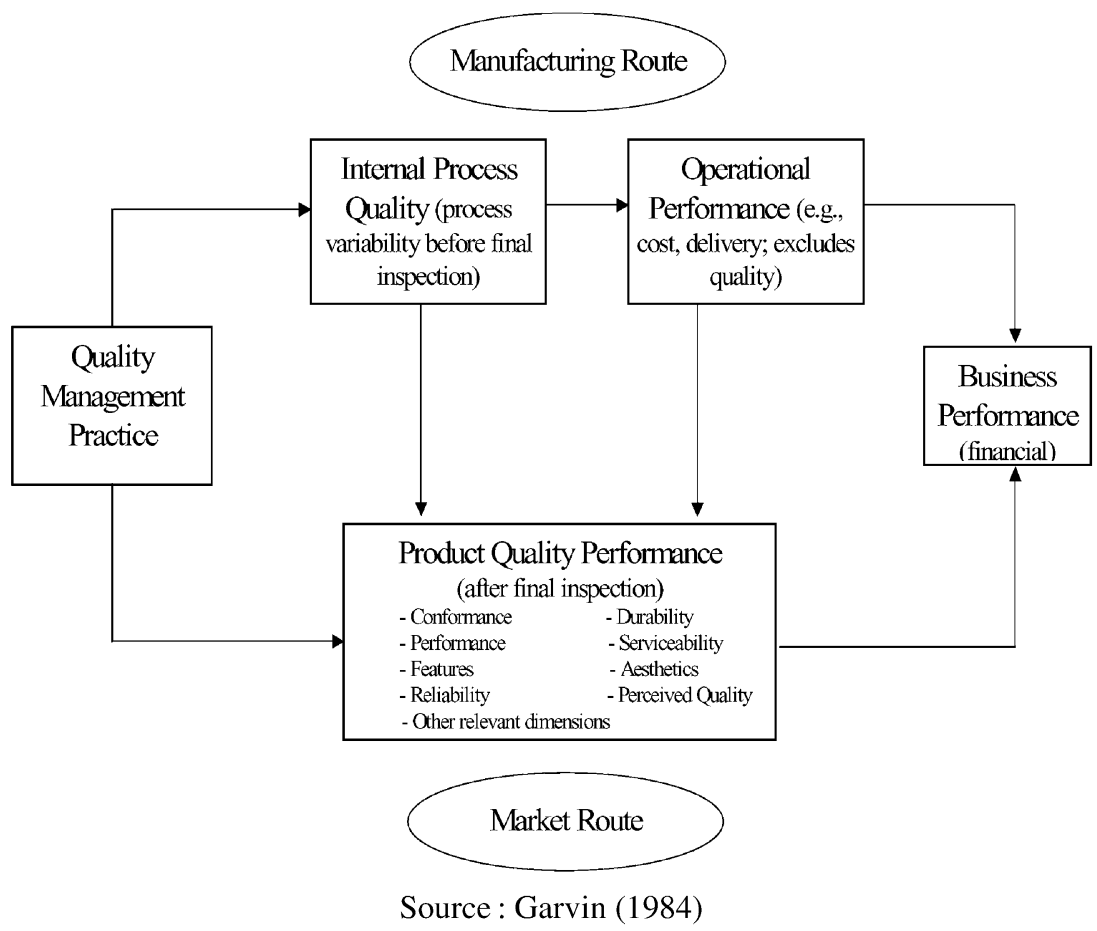

Fig. 1. The quality performance model.

can lead directly to improved business performance. Finally, improved product quality can lead to lower warranty and product liability costs, resulting in lower service costs and improved business performance.

The following sections review empirical evidence on two main sets of relationships depicted in the quality performance model: (i) the impact of quality performance (internal process quality and product quality) on operational and business performance; and (ii) the impact of QM practice on performance (internal process quality, product quality, operational and business performance). The first two sections summarize the evidence which is then discussed at the end.

\section{The impact of quality performance on operational and business performance: empirical evidence}

This research stream can be traced to the seminal study of Phillips et al. (1983) which was then followed by a flurry of similar studies during the 1980s. Capon et al. (1990) summarized all this work using meta-analysis to examine published studies of factors affecting financial performance. Recently, there have been more rigorous empirical studies with the explicit goal of testing relationships between quality and operational and business performance (Maani et al., 1994; Sluti et al., 1995; Madu et al., 1995; White, 1996). Table 3 summarizes these studies.

\section{The impact of quality management practice on performance: empirical evidence}

While the above research examined the relationship between quality performance and operational and business performance, other researchers have worked further upstream in the quality performance model by studying the relationship between QM practice and performance (internal process quality, product quality, operational and business performance). Much of the early literature was descriptive, and evidence of links between QM practices and performance was in the most part anecdotal. More recently, there have been more elaborate efforts to substantiate these relation- 
Table 3

Summary of the empirical evidence on the relationship between quality performance and operational and business performance

\begin{tabular}{|c|c|c|c|c|}
\hline \multirow[t]{2}{*}{ Study } & \multirow[t]{2}{*}{ Methodology } & \multirow[t]{2}{*}{ Sample } & \multicolumn{2}{|c|}{$\begin{array}{l}\text { Findings related to the impact of quality } \\
\text { performance on }\end{array}$} \\
\hline & & & Operational performance & Business performance \\
\hline Capon et al. (1990) & Meta-analysis & $\begin{array}{l}20 \text { published studies } \\
\text { relating quality to } \\
\text { business performance }\end{array}$ & Not addressed & $\begin{array}{l}\text { In the sample of studies } \\
\text { there were } 104 \text { positive, } \\
\text { versus } 8 \text { negative, } \\
\text { relationships between quality } \\
\text { and business performance }\end{array}$ \\
\hline $\begin{array}{l}\text { Maani et al. (1994), } \\
\text { Sluti et al. (1995) }\end{array}$ & $\begin{array}{l}\text { Survey study, structural } \\
\text { equation modeling }\end{array}$ & 184 manufacturing firms & $\begin{array}{l}\text { Conformance quality had a } \\
\text { significant and strong effect }\end{array}$ & $\begin{array}{l}\text { Conformance quality had a } \\
\text { significant but weak effect }\end{array}$ \\
\hline Madu et al. (1995) & $\begin{array}{l}\text { Survey study, path } \\
\text { analysis }\end{array}$ & 146 manufacturing firms & Not addressed & $\begin{array}{l}\text { Significant effect of quality } \\
\text { performance (customer } \\
\text { satisfaction, employee } \\
\text { satisfaction and employee } \\
\text { service quality) }\end{array}$ \\
\hline White (1996) & Meta-analysis & $\begin{array}{l}\text { Previous studies providing } \\
\text { empirical evidence of } \\
\text { relationships between } \\
\text { conformance quality and } \\
\text { business performance }\end{array}$ & $\begin{array}{l}\text { Strong support for the } \\
\text { beneficial effect of } \\
\text { conformance quality }\end{array}$ & $\begin{array}{l}\text { Less strong, but still positive } \\
\text { support for the beneficial } \\
\text { effect of conformance quality }\end{array}$ \\
\hline
\end{tabular}

ships, using sophisticated data collection and analysis approaches to move beyond description to inference. Flynn et al.'s (1995a) categorization of the role of QM practices into core and infrastructure (infrastructure practices create an environment supportive of the use of core practices) proved to be enlightening in interpreting and comparing the results of these studies. Table 4 summarizes the major rigorous empirical studies directly addressing the impact of QM practices on performance.

\section{Conclusions and further research}

Overall, the studies on the relationship between quality performance and firm performance (Table 3 ) suggest that: (i) quality performance (mainly conformance quality) has a significant and strong effect on operational performance; and (ii) quality performance has a weak and not always significant effect on business performance. In turn, the studies on the relationship between $\mathrm{QM}$ practice and performance (Table 4) seem to indicate that, as a whole, QM practices have a significant and strong impact on quality and operational performance. However, the impact of QM practices on business performance is weaker and not always significant.
The results of these two sets of studies are remarkably consistent and, although causality cannot be established, taken together they seem to suggest the following. First, QM practices have a significant and strong impact on quality (internal process and product) and operational performance. Second, the indirect impact of QM practices on business performance via the mediating effect of quality and operational performance, although significant, is weaker, and still leaves a reasonable amount of business performance variance unexplained.

The weak impact of QM practices on business performance is open to two different interpretations. In the first possible interpretation, QM practice may indeed be beneficial to business performance, i.e. quality may be free-and its weak impact reported in empirical studies attributed to research methodology. Hackman and Wageman (1995) list several difficulties in detecting statistically the direct effects of QM by using outcome criteria such as business performance.

A second interpretation may be that the impact of QM practice on business performance is contingent on other factors, such as the nature of the market environment (e.g. in terms of market size and structure, e.g. perfect competition versus monopoly) (Karmarkar and Pitbladdo, 1997). According to this 
Table 4

Summary of the empirical evidence on the relationship between QM practices and performance

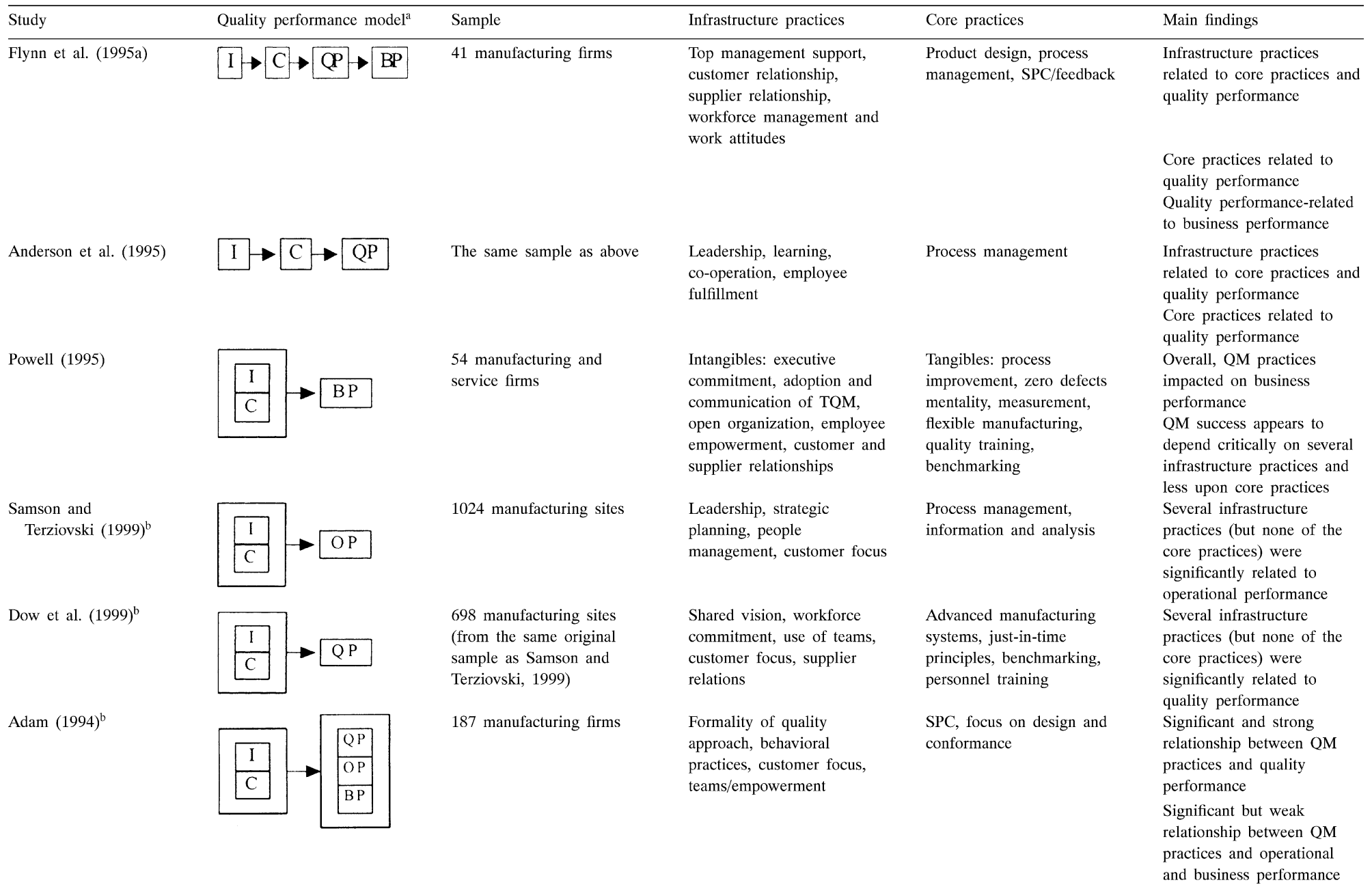


Adam et al. (1997)

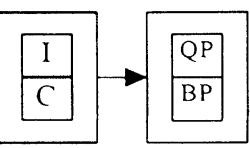

997 manufacturing firms

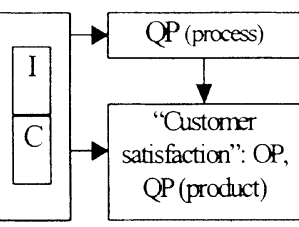

Hendricks and Singhal (1997)

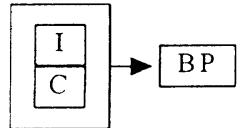

Dean and Snell (1996)

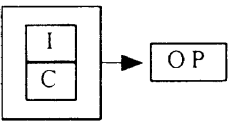

339 manufacturing plants Strategic quality planning,
human resource managemen

463 firms that have won quality awards

160 manufacturing firms

No explicit measurement of

QM practices. Winning of

quality awards is taken as a

proxy for the effective

implementation of QM

QM measured as a single
Senior executive involvemen

mployee involvement,

employee satisfaction,

employee selection and

development, compensation,

customers

Process quality
and analysis

construct reduction
Design and conformance, quality knowledge, invento

Significant and strong impact of QM on quality

performance

Significant but weak impact of QM on business

performance

QM practices have

significant impact on

internal process quality and customer satisfaction

No significant relationship

between internal process

quality and customer

satisfaction

QM practices have a

significant impact on

business performance

Use of QM was directly

related to perceived

operational performance

${ }^{a} \mathrm{C}$, core practices; I, infrastructure practices; QP, quality performance; OP, operational performance; BP, business performance.

${ }^{\mathrm{b}}$ Study does not explicitly categorize practices into core and infrastructure. The presented classification is given by the authors. 
interpretation, quality may not always be free. That is, although the quality performance model delineates possible mechanisms by which increased quality performance may lead to increased operational and business performance, it should not be taken for granted that the final result of these mechanisms will always be increased performance. Within this paradigm, quality improvements should be assessed by the return on the investment made as any other productivity enhancing or cost reducing initiative (Karmarkar and Pitbladdo, 1997). This is in line with Juran's ideas on optimal quality, according to which there is an optimum level of conformance quality above which it ceases to be advantageous for firms to invest in improving internal process quality (Juran, 1988). Although conceptually it is difficult to challenge this view, the relevant issue is to identify under which conditions quality may not be free and whether these conditions are bound to occur frequently in real business settings. Following from this, there is the need to test the relationships in the quality performance model across different business contexts.

The findings listed in Table 4 also raise questions about the interplay between core and infrastructure practices. Existing theory points to core and infrastructure practices both having to be present to produce success. Spencer (1994), Sitkin et al. (1994) and Dean and Bowen (1994) all defend the integration of mechanistic/process/technical ("core") and non-mechanistic/sociobehavioral ("infrastructure") QM aspects. Hackman and Wageman (1995) also note the utility of quality tools and techniques (core elements) as auxiliary for learning. According to this view, the infrastructure components of QM may only have a positive effect on performance if core aspects have also been established, i.e. the infrastructure aspects seem to work through the core aspects to produce improvements

While this view is consistent with the empirical results of Flynn et al. (1995a) and Anderson et al. (1995), other studies have raised doubts about the contribution of core practices to performance, suggesting that infrastructure practices can produce performance even without the core practices (Powell, 1995; Dow et al., 1999; Samson and Terziovski, 1999). However, the research design used by the latter studies was not adequate to draw any definite conclusions, because the quality performance model in which they were based did not allow for the separation of direct effects of infrastructure practices on performance from indirect effects of these practices through the core practices.

For example, Powell (1995) suggests that only infrastructure practices may contribute to business performance because they are difficult to imitate, while core practices are not. Powell (1995) based his doubts about the effectiveness of core practices on the fact that the best performers in terms of business performance in his sample had a significantly higher degree of adoption of the infrastructure practices than the worse performers. However, there was no significant difference in the degree of adoption of core practices. This leaves scope for an alternative explanation. Infrastructure practices are indeed necessary to support and enhance the effects of core practices on performance. But they might not be sufficient: firms only adopting the infrastructure practices may not achieve a good level of performance. What may be difficult to imitate may not only be the infrastructure practices per se, but its integration with the core practices. Dow et al.'s (1999) and Samson and Terziovski's (1999) studies suffered from similar deficiencies. For example, Samson and Terziovski (1999) found that the only practices that were related to performance were infrastructure practices; however, the usage of core practices was found to be strongly correlated with the use of the infrastructure practices, thus, casting doubts over the separation of the effects of each of the sets of practices. Therefore, further research is needed to clarify the relative importance and the interplay between core and infrastructure practices in determining performance.

Future research in the quality performance model also needs to address some of the deficiencies of past studies. First, there is a need to clearly situate studies within the practice performance model by indicating which parts of the model the studies are addressing. Several studies address only a few variables of the model and ignore potentially important effects of other variables (e.g. research relating $\mathrm{QM}$ practice to business performance without considering quality and operating performance).

Second, "quality" needs to be clearly defined in each study. The word "quality" is used to mean different things in different studies such as internal process quality, one or several dimensions of product quality, customer satisfaction and operational performance. Universalistic propositions describing the 
relationship among various variables and quality cannot be made when the meaning of quality continually changes. Some of the conflicting results reported in the literature linking quality to performance outcomes may be largely attributable to definitional deficiencies (Reeves and Bednar, 1994).

Finally, we need to increase our understanding of the means by which QM effects are generated. In this connection, three areas need more investigation. First, more research into the linkages between the several QM practices is needed. Most research to date dealing with specific QM practices tends to ignore their relationship with other practices (e.g. SPC as dissociated from workforce management). Second, we need to know more about the interaction between QM and other best practices. One of the few empirical studies in this area is Flynn et al. (1995b) who looked at the interaction between JIT and QM. Third, one important factor in the practice performance model needs to be further researched, namely, the time lags between the implementation of QM practice and performance (e.g. Reed et al., 1996). Given the integrative and complex nature of this type of research, the field might benefit from case study research using process criteria (the degree to which improvements in organizational functioning that are expected are actually observed; Hackman and Wageman, 1995) to measure QM effectiveness, as opposed to outcome criteria.

\section{Quality management in the context of management theory}

Although the field of QM has been mainly led by practitioners, recently there have been efforts to bridge the gap between practice and theory with an emphasis on research attempting to situate $\mathrm{QM}$ in the context of management theory (MT) of which the special issue of the Academy of Management Review in 1994 is a landmark. Four pieces of work stand out as the most elaborate and explicit efforts in comparing QM and MT at the detailed topic level (Dean and Bowen, 1994; Anderson et al., 1994; Hackman and Wageman, 1995; Waldman, 1994). Across these four works, several QM topics were systematically compared to MT. Table 5 summarizes the main conclusions of these studies, following Dean and Bowen's (1994) classification of topics along the content areas of the Baldrige
Award framework. These studies found areas in which QM and MT are essentially similar; and areas of discrepancy between QM and MT: areas in which MT could offer insights into QM (most notably, strategic quality planning and human resource management), areas where QM raises questions for further development in MT; and clear conflict areas between QM and MT.

Other studies have compared QM to MT at a more general level. Spencer (1994) examines several QM components to conclude that QM comprises elements from both the mechanistic and organismic models of organization. Similarly, Grant et al. (1994) state that QM can bridge the gap between the "rationalist" school (based on the principles of scientific management and the theory of bureaucracy) and the "human relations" school (based on the role of the organization as a social system, emphasizing psychological and social needs). It, thus, seems that QM holds potential to inform MT, in that it seems to retain some of what is valuable in traditionally opposing models of organization while discarding some of their negative aspects (Spencer, 1994).

Several important points arise from the theoretical developments described above. First, QM in its pure form (as first envisaged by its founders) may not be synonymous with current best practice. As stated earlier, there seems to be areas where QM could receive insights from MT. Moreover, practitioners, who have traditionally led the QM field, are merging pure QM with other practices prescribed by MT (e.g. performance-related compensation, benchmarking) (Hackman and Wageman, 1995). Furthermore, empirical studies using definitions of QM not strictly based on the founders of the movement and incorporating practices in actual use have shown a link between the use of these practices and performance (e.g. Flynn et al., 1995a; Ahire et al., 1996; Black and Porter, 1996). Whether these deviations from pure QM are implementation deficiencies threatening performance-as defended by some authors (e.g. Kolesar, 1995) — or a worthy modification of the original QM recommendations needs to be ascertained.

Second, QM seems to be able to offer insights into MT, especially in what concerns the pragmatic integration of aspects from traditionally opposing schools of management theory (Spencer, 1994; Grant et al., 1994). Finally, there are unresolved conflicts between 
Table 5

Comparison between quality management (QM) and management theory (MT) along the content areas of the Baldrige Award framework

\begin{tabular}{ll}
\hline QM topic & Areas of agreement between QM and MT \\
\hline Leadership & $\begin{array}{l}\text { Similarity of QM's top management leadership with } \\
\text { the transformational leadership concept of MT (Dea }\end{array}$
\end{tabular}
the transformational leadership concept of MT (Dea and Bowen, 1994; Anderson et al., 1994; Waldman, 1994)

Customer focus and satisfaction

Strategic quality planning

QM's concept of learning is similar to the concept of first-order learning of the organizational learning theory (single-loop, top-down) (Anderson et al., 1994; Hackman and Wageman, 1995)

QM's concept of continuous improvement is similar to the concept of incremental innovation and is consistent with the process innovation literature (Anderson et al., 1994)
Areas of disagreement between QM and MT

QM assigns less importance to leadership's role further down the hierarchy. QM seems to be portrayed as a substitute for leadership at lower organizational levels (Dean and Bowen, 1994). QM $\neq$ MT

QM ignores transactional type of leadership (Dean and Bowen, 1994). QM $\neq$ MT MT generally ignores the role of customers (Dean and Bowen, 1994). QM > MT The marketing literature treats quality in terms of a single attribute in a static environment; to QM, quality is based upon multiple attributes that evolve over time (Anderson et al., 1994). QM $\neq$ MT

The economics literature associates higher quality to higher costs, while $\mathrm{OM}$ does not necessarily do so (Anderson et al., 1994). QM $\neq$ MT

MT advocates that strategy formulation should include careful assessment of organizational strengths and weaknesses, not just customer expectations (Dean and Bowen, 1994). MT > QM

QM portrays quality as the main source of competitive advantage driving improvements on other sources of competitive advantage. To MT, quality is a potentially important source of competitive advantage, but only one among many (Dean and Bowen, 1994). MT > QM

QM deals extensively with business unit strategy (how to compete for a set of customers) but is generally silent on corporate strategy (how to decide which customers to compete for) (Dean and Bowen, 1994). MT > QM

QM assumes that the processes of strategic formulation and implementation can be continuously improved. MT implicitly assumes that strategic processes are a product of relatively stable organizational conditions (e.g. size, structure), and that firms will not be able to change them (Dean and Bowen, 1994). QM $\neq$ MT QM emphasizes strategy implementation (deployment); MT emphasizes strategic content. MT should devote more attention to strategy implementation (Dean and Bowen, 1994). QM > MT

MT theory should increase coverage of process and technical factors (both addressed by $\mathrm{QM}$ ) which are currently undervalued when compared to social aspects (Dean and Bowen, 1994). QM > MT

While MT proposes incremental innovation as suitable for mature products and industries, QM advocates incremental innovation over a wider span of the product life cycle (Anderson et al., 1994). QM $\neq$ MT 
Information and analysis

Human resource management

QM is similar in approach to MT's literature on analysis and evaluation, and career managemen (Dean and Bowen, 1994; Waldman, 1994)

The QM assumption that people naturally care abou their work is supported by the theory $\mathrm{Y}$ perspective on human behavior (Anderson et al., 1994) employee involvement, use of teams, training needs

QM's concept of learning departs from the concept of second-order learning of organizational learning theory (Anderson et al., 1994). MT > QM

Supplier relationships: MT advocates that supplier relationships should be designed using a contingency approach, rather than assumed to be universally appropriate (Dean and Bowen, 1994). MT > QM

Resource dependence theory and transaction cost theory prescribe competitive, as opposed to co-operative, relationships between organizations (Anderson et al.,

1994). QM $\neq$ MT

QM over relies on formal analysis of information, especially in ambiguous and political settings (Dean and Bowen, 1994). MT > OM

QM points to the need to develop prescriptive theories of decision making and information processing in the realm of MT (Dean and Bowen, 1994). QM > MT

MT advocates that employee involvement and empowerment initiatives should be designed using a contingency approach, rather than assumed to be universally appropriate (Dean and Bowen, 1994). MT > QM

QM and MT posit different relative contributions of person and system factors to performance. QM emphasizes system factors while MT traditionally emphasizes person factors. This situation is reflected in different HRM practices such as, selection-the HRM literature advocates the selection of employees with the cultural norms and values akin to QM such as flexibility, the desire to learn and solve problems, and a team orientation; selection is generally not addressed by QM performance appraisal and compensation- $\mathrm{QM}$ proponents have aversion to individual incentive programs and related practices such as individualized goal setting. The HRM literature proposes a contingency approach according to which the emphasis on person versus system factors should depend on hierarchical level and autonomy (Dean and Bowen, 1994; Waldman, 1994). MT > QM

QM argues against competitive behavior and conflict. MT (social interdependency theory) supports internal co-operation, but also admits that internal competition among individuals can be positive (Anderson et al., 1994). QM $\neq$ MT

The following QM aspects are inconsistent with motivational theories in the organizational literature, and according to this literature may impact negatively on worker motivation: restricted autonomy of workers in determining the means by which work is accomplished, with QM's emphasis on identifying the best work practices (those that bring work processes under the greatest possible

control) and subsequent standardization and diffusion across the organization; a control) and subsequent standardization and diffusion across the organization; a
exaggerated focus on processes out of control, with seldom explicit setting of positive challenging goals; and no performance-related pay (Hackman and Wageman, 1995). QM $\neq$ MT

Sources: Dean and Bowen (1994), Anderson et al. (1994), Waldman (1994) and Hackman and Wageman (1995).

${ }^{a} \mathrm{QM} \neq \mathrm{MT}$ : indicated by authors as conflict areas between QM and MT. MT > QM: indicated by authors as limitations of the practice of QM in the light of MT; areas in which MT could offer insights into the practice of QM. QM > MT: indicated by authors as areas the practice of QM raises questions for further development in MT. 
QM and MT in some areas (Table 5). Further research needs to be undertaken to ascertain whether MT should incorporate insights from QM or QM principles and prescribed practice should be modified in light of MT. It has also been suggested that some of the conflicts between QM and MT arise because of the universal orientation of QM, which contrasts with the contingent approach of MT (Dean and Bowen, 1994). Contingency research into QM may be a promising avenue to solve some of these conflicts.

\section{The implementation of quality management}

The implementation of QM in an organization requires two distinct types of decisions: what to do (content: the extent to which the different $\mathrm{QM}$ practices should be used) and how to do it (process: how to conduct the change process by which the chosen QM practices are embedded in an organization). We review the literature concerning these two aspects of QM implementation and discuss them jointly at the end.

\section{QM implementation content—what to do}

Having been strongly led by practitioners since its inception, QM has acquired a strong prescriptive stance, with the whole set of QM practices often being advocated as being universally applicable to organizations. The logical implication is that organizations should adopt and use the whole set of QM practices to the same (high) degree, regardless of their context.

Recently, however, more rigorous academic studies have started to question the universal validity of QM practices, investigating the influence of the organizational context on QM practice. Only four studies were found that rigorously addressed this issue within an explicit contingency framework (Benson et al., 1991; Sitkin et al., 1994; Reed et al., 1996; Sousa, 2000; Sousa and Voss, in press). All of them suggest that the effectiveness of individual QM practices is contingent on the organizational context. Relevant contextual variables include managerial knowledge, corporate support for quality, external quality requirements and product complexity (Benson et al., 1991), organizational uncertainty (Sitkin et al., 1994; Reed et al., 1996) and manufacturing strategy context (Sousa, 2000; Sousa and Voss, in press). Other stud- ies, whose main purpose was not to investigate QM contingencies, have tangentially uncovered other contextual factors affecting QM practices, such as industry (Maani, 1989; Powell, 1995), firm size (Price and Chen, 1993; Madu et al., 1995), years since adoption of QM programs (Powell, 1995; Ahire, 1996), country (Madu et al., 1995), and product/process factors (e.g. manufacturing system: Maani, 1989; type of work an organization does: Lawler, 1994; breadth of product line and frequency of product changes: Kekre et al., 1995).

In addition, several large scale empirical studies examining the impact of QM on firm performance have found that some QM practices did not have a significant impact on performance (e.g. Powell, 1995; Dow et al., 1999; Samson and Terziovski, 1999), some of them suggesting that this may be due to these practices being context dependent (Powell, 1995; Dow et al., 1999).

In conclusion, the existing literature on QM contingencies, although sparse, clearly raises the possibility of individual QM practices being context dependent. However, only two studies (Benson et al., 1991; Sousa, 2000) have directly addressed this issue empirically, pointing to the need to conduct more empirical studies of this sort. Such studies should aim at identifying important contingency variables that distinguish between different types of organizational contexts and producing guidelines on which practices to emphasize in each of them.

\section{QM implementation process_-howtodoit}

The QM practitioner literature abounds with reports of problems in (the process of) implementing QM. For example, Harari (1993) and MacDonald (1993) listed reasons why QM may not work, Papa (1993) suggested that after 18 months or so, QM practices can revert to the old ways, and Myers and Ashkenas (1993) discussed ways to stop QM from becoming another expensive and unproductive fad. Empirical studies also uncovered implementation problems (e.g. Van de Wiele et al., 1993). In parallel, several authors share the view that successful implementation of QM requires a radical change (e.g. Dobyns and Crawford-Mason, 1991; Munroe-Faure and Munroe-Faure, 1992; Reger et al., 1994) resulting in a paradigm shift that may bring into question 
members' most basic assumptions about the nature of the organization (Blackburn and Rosen, 1993). According to this view, QM cannot simply be grafted onto existing management structures and systems, and may require the redesign of work, the redefinition of managerial roles, the redesign of organizational structures, the learning of new skills by employees at all levels, and the reorientation of organizational goals (Grant et al., 1994). Thus, the prevalent view seems to be that QM is difficult to implement.

A tremendous wealth of advice is available on how a company can go about implementing QM. Works in this area include experience-based recommendations (e.g. Fenwick, 1991; Dawson, 1995; Davis, 1997), lessons based on case studies (e.g. Instone and Dale, 1989; De Cieri et al., 1991; McDonnell, 1992), identification of barriers to implementation (e.g. Oakland and Sohal, 1987; Eisen et al., 1992; Whalen and Rahim, 1994), and reasons why QM programs fail (e.g. Harari, 1993; MacDonald, 1993).

This literature, however, suffers from two main shortcomings. First, lack of academic rigor, illustrated by the rare presence of a methodology section in published studies and the absence of a clear definition of what is meant by QM content wise. Studies have usually been exploratory, descriptive and/or prescriptive in nature. Second, and related to the first deficiency, these studies have been unable to offer a series of underlying threads and principles which apply irrespective of the characteristics of the company.

Although these studies were useful in the first stages of research, we now need to raise the theoretical and methodological level of QM implementation research and attempt to produce more general principles. We propose two main courses of action to accomplish this. First, to develop theoretical frameworks that can structure and guide research beyond the exploratory level towards theory building. In this endeavor, researchers may find it fruitful to draw on existing theories. For example, Reger et al. (1994) draw on cognitive theory to build a conceptual framework for understanding impediments to implementing QM which they then use to produce powerful and general propositions regarding QM implementation. A promising theoretical source which has not yet been adequately explored is the existing literature on the management of organizational change (e.g. Tushman and Romanelli, 1985; Mohrman et al., 1989).
Second, there is the need to conduct contingency studies. While there may be no one best implementation approach to suit all organizations and each company may need a tailored implementation program (e.g. Van der Akker, 1989; Atkinson, 1990), it may be possible to derive general principles that apply to particular categories of companies. In this connection, research should identify which are the relevant contextual factors to be considered and their links to the choice of the implementation approach (e.g. Mann and Kehoe, 1995; Yusof and Aspinwall, 2000).

\section{Conclusions and further research}

Although the implementation of QM requires decisions in the above two areas, the respective research streams have largely progressed ignoring each other. On the one hand, research on "what to do" has began to provide only a static view, offering so far only limited insights on how the end result should look like content-wise for the organizations embarking on the QM journey. What it has as yet failed to produce are guidelines on what practices should be emphasized by organizations at difference stages of QM maturity and on what might be the best QM practice implementation sequence to reach the end result.

On the other hand, the "how to do it" research stream has taken for granted that all QM practices are universally applicable. Implicit in their view is that it is always possible and worth changing an organization's context to accommodate all QM practices as espoused. However, research on "what to do" suggests that there may be innate organizational characteristics resulting, e.g. from the nature of the markets, business strategy, or process hardware that cannot or are very difficult to change in order to accommodate standard QM. Some of the difficulties and problems in implementing QM reported in the literature may in fact not simply be an inevitable pain that organizations have to endure in moving towards quality, but they may result instead from too great a mismatch between the universally espoused form of QM and the particular organizational context. It is important to clearly differentiate these difficulties from those arising from the change process, because they may demand different courses of action. In particular, context induced difficulties may be seen as requiring "structural fixes" along one or both of the following two dimensions: the mix of QM 
practices to adopt and/or the modification of adverse context characteristics (Sousa, 2000). These measures are clearly different from measures attempting to facilitate the implementation process, such as leadership or training issues.

The integration of the two research streams emerges as the main challenge facing QM implementation research and one which would contribute to structuring the current chaotic wealth of QM implementation advice and to producing more solid and useful advice to managers.

\section{Overall conclusions and future research}

We have organized and reviewed QM research in five areas: the definition of QM, the definition of product quality, the impact of QM on firm performance, QM in the context of management theory and the implementation of QM. In each of them, we explored suggestions for future research. In reflecting on the field as a whole, we would like to re-visit our initial three fundamental questions.

First, is whether there is such a field as QM. We concluded that QM, as espoused by its founders, can be reliably distinguished from other strategies for organizational improvement and there is substantial agreement in the literature as to which practices fall under the QM umbrella. Regarding QM's immediate output, product quality, we saw that existing research still had to overcome some definitional deficiencies, namely, it should begin to carefully choose and clearly state the definition of quality used and to treat quality as a multi-dimensional construct. Overall, QM researchers now seem to have ironed out most of the existential issues and laid out solid conceptual foundations for what might indeed be considered a maturing field of study. The future research that we recommended in this area amounts to further developing the already established foundations, including the need to distinguish between QM principles, practices and techniques, the need to standardize the vocabulary, the need to test the existing instruments to measure QM practice dimensions in still less well studied contexts and the need to develop more precise definitions and multi-dimensional measures of product quality for different contexts.

Our second fundamental question is whether the set of practices associated with QM is valid as a whole.
The many problems reported in implementing QM legitimately raise the question of whether these are the result of conceptual flaws in QM or of implementation deficiencies. Most authors recognize the virtues of QM and attribute failures to implementation problems, such as non-committal executives (e.g. Barclay, 1993; Hackman and Wageman, 1995; Masterson et al., 1997; Samson and Terziovski, 1999). Research on the relationship between QM practices and performance also points to the overall set of $\mathrm{QM}$ practices being valid, although being difficult to implement and being potentially subject to contingencies. In this area, we identified the need for a more detailed and solid understanding of QM's performance effects by using finer quality performance models (including all of the relevant variables and relationships), investigating the models' relationships across different contexts, further studying the interplay between core and infrastructure practices, looking at the interactions between QM practices between them and with other sets of best practices, and investigating the mechanisms (and time lags) by which QM practices affect performance.

The research on comparing QM to existing management theory reinforces the overall validity of $\mathrm{QM}$, but simultaneously raises doubts as to whether the original recommendations could be improved by incorporating insights from existing theory and practitioners in the field. In addition, in the present business environment there are increasing pressures to stretch and add to the content of QM. These may be due partly to an effort by practitioners to re-package QM and make it more sellable after its initial hype and partly to the real needs of current businesses. We mentioned earlier the evolution of the quality award assessment frameworks to increasingly include topics which are strictly not quality related. Simultaneously, in an effort to apply QM to non-traditional settings (e.g. fundamentally uncertain contexts or contexts where creativity is paramount) new practices are being suggested for inclusion as part of QM (e.g. Sitkin et al.'s (1994) Total Quality Learning practices). In addition, in the present business environment, the attention of businesses is increasingly being directed away from within-firm boundaries towards the management of supply chains and networks of firms. These are areas outside the traditional realm of QM, despite its concerns with the immediate links to customers and suppliers. This general trend poses a major challenge for the future of the field of QM. 
Either it keeps adding to the core of QM-carrying with it the danger of dissolving QM's identity as a field of study and threaten the soundness of the field's conceptual foundations - or it begins to frame the much needed research in these new areas as research conducted at the interface between core QM and other fields.

Despite eventually benefiting from improvements and additions, the main body of literature points to the overall validity of QM. Accepting this premise brings us to our third fundamental question: How to implement QM in a real business setting? Here, we identified the pressing need to structure the current chaotic wealth of implementation advice and produce more solid and useful advice to managers. In this connection, we concluded that more empirical research on the content of QM implementation was necessary. The aim should be to better understand the effect of contextual variables on the effectiveness of individual QM practices with the objective of producing guidelines on how to adapt QM content to an organization's specific context. We also pointed out the need to raise the rigor and theoretical level of research on the process of implementation of QM. However, the major challenge we identified was to integrate the content and process streams of QM implementation research.

Overall, the research needs discussed above all point to the overarching need to develop sounder, richer and more detailed knowledge on QM. This is a natural course for a maturing field of study. After QM's initial hype and exploratory stages, many businesses have come to mistrust the quick fix and somewhat superficial recipes that have often been associated with QM. As researchers, we need to reinforce QM's validity by offering more sober and substantiated knowledge. We suggest two general avenues to accomplish this.

First, to conduct more contingency studies that will help managers tailor the existing QM knowledge to their particular organizational context. The need to produce contingency knowledge was a recurring theme in our review of the several QM research streams. Examples include the need to test the existing instruments to measure QM practice dimensions in still less well studied contexts; the need to develop definitions and multi-dimensional measures of product quality for different contexts; the need to investigate relationships in the practice performance model across different contexts; conducting contin- gency research as a promising way to solve some of the identified conflicts with management theory; and the need to develop QM implementation guidelines for different contexts.

Second, sound and rich knowledge needs to be backed by stronger theory. Although QM's theory grounding has been increasing in recent years, we have identified many areas that still need more knowledge through theory building. In this connection, establishing links to other theoretically more developed fields may be of benefit. As the theory content of QM increases, there is also the need for more theory testing research. This could take the form of replication studies (e.g. Rungtusanatham et al., 1998) and testing existing theories in new settings (contingency research).

The generation of deeper and richer knowledge should be backed up by rigorous research methods and carefully chosen research designs. Although the trend has been in this direction, there are still research areas that especially lack academic rigor and are geared towards descriptive type studies, such the one on the process of QM implementation. The field needs to keep increasing the use of more sophisticated methodological tools to enable the transition from description to making sound inferences. This may include the use of more rigorous data analysis methodologies, both quantitative (e.g. structural equation modeling, Flynn et al., 1995a) and qualitative (e.g. causal network analysis of case study data, Sousa, 2000).

We hope that our review, by organizing research into five main themes and structuring existing knowledge, will contribute to eliminating some of the identified deficiencies of current research, such as definitional difficulties relating to product quality, poor positioning of studies in the quality performance model or lack of research controls for important contextual factors. In addition, we trust that our reflective review will foster progress towards a more integrative QM theory, by stimulating the forging of links and the integration of knowledge in the five streams of research that we have considered. We have extracted some interesting insights by comparing findings across these several streams, but much more proactive work along these lines needs to be conducted.

To conclude, we hope that our reflections will help reinforce the importance of QM as a field of study and will help it affirm as a major best practice 
tool kit that should be in place in most if not all organizations.

\section{References}

Adam, E., 1994. Alternative quality improvement practices and organisation performance. Journal of Operations Management $12,27-44$.

Adam, E., Corbett, L., Flores, B., Harrison, N., Lee, T., Rho, B., Ribera, J., Samson, D., Westbrook, R., 1997. An international study of quality improvement approach and firm performance. International Journal of Operations and Production Management 9 (17), 842-873.

Ahire, S., 1996. TQM age versus quality: an empirical investigation. Production and Inventory Management Journal, $18-23$.

Ahire, S., Landeros, R., Golhar, D., 1995. Total quality management: a literature review and an agenda for future research. Production and Operations Management, 277-307.

Ahire, S., Golhar, D., Waller, M., 1996. Development and validation of TQM implementation constructs. Decision Sciences 27 (1), 23-56.

Anderson, J., Rungtusanatham, M., Schroeder, R., 1994. A theory of quality management underlying the Deming management method. Academy of Management Review 19 (3), 472-509.

Anderson, J., Rungtusanatham, M., Schroeder, R., Devaraj, S., 1995. A path analytic model of a theory of quality management underlying the Deming management method: preliminary empirical findings. Decision Sciences 26 (5), 637-658.

Atkinson, P., 1990. Creating Culture Change: The Key to Successful Total Quality Management. IFS Publications, Bedford.

Barclay, C., 1993. Quality strategy and TQM policies: empirical evidence. Management International Review, (1), 87-98.

Benson, G., Saraph, J., Schroeder, R., 1991. The effects of organisational context on quality management: an empirical investigation. Management Science 37 (9), 1107-1124.

Black, S., Porter, L., 1996. Identification of the critical factors of TQM. Decision Sciences 27 (1), 1-21.

Blackburn, R., Rosen, B., 1993. Total quality and human resources management: lessons learned from Baldridge award-winning companies. Academy of Management Executive 7 (3), 49-66.

Capon, N., Farley, J., Hoenig, S., 1990. Determinants of financial performance: a meta-analysis. Management Science 36 (10), 1143-1159.

Choi, T., Eboch, K., 1998. The TQM paradox: relations among TQM practices, plant performance, and customer satisfaction. Journal of Operations Management 17, 59-75.

Davis, T., 1997. Breakdowns in total quality management: an analysis with recommendations. International Journal of Management 14 (1), 13-22.

Dawson, P., 1995. Implementing quality management: some general lessons on managing change. Asia Pacific Journal of Quality Management 4 (1), 35-46.

De Cieri, H., Samson, D., Sohal, A., 1991. Implementation of TQM in an Australian manufacturing company. International Journal of Quality and Reliability Management 8 (5), 55-65.
Dean, J., Bowen, D., 1994. Managing theory and total quality: improving research and practice through theory development. Academy of Management Review 19 (3), 392-418.

Dean, J., Snell, S., 1996. The strategic use of integrated manufacturing: an empirical examination. Strategic Management Journal 17 (6), 459-480.

Dobyns, L., Crawford-Mason, C., 1991. Quality or Else: The Revolution in World Business. Houghton-Mifflin, Boston.

Dow, D., Samson, D., Ford, S., 1999. Exploding the myth: do all quality management practices contribute to superior quality performance? Production and Operations Management 8 (1), $1-27$.

Eisen, H., Mulraney, B., Sohal, A., 1992. Impediments to the adoption of modern quality management practices. International Journal of Quality and Reliability Management 9 (5), 17-41.

Fenwick, A., 1991. Five easy lessons: a primer for starting a total quality management program. Quality Progress 24 (12), 63-66.

Flynn, B., Schroeder, R., Sakakibara, S., 1995a. The impact of quality management practices on performance and competitive advantage. Decision Sciences 26 (5), 659-692.

Flynn, B., Sakakibara, S., Schroeder, R., 1995b. Relationship between JIT and TQM: practices and performance. Academy of Management Journal 38 (5), 1325-1360.

Garvin, D., 1984. What does product quality really mean? Sloan Management Review, 25-43.

Garvin, D., 1987. Competing on the eight dimensions of quality. Harvard Business Review 65, 202-209.

Grant, R., Shani, R., Krishnan, R., 1994. TQM's challenge to management theory and practice. Sloan Management Review, $25-35$.

Hackman, J., Wageman, R., 1995. Total quality management: empirical, conceptual, and practical issues. Administrative Science Quarterly 40, 309-342.

Harari, O., 1993. Ten reasons why TQM doesn't work. Management Review 82 (1), 33-38.

Harvey, J., 1998. Service quality: a tutorial. Journal of Operations Management 16 (5), 583-597.

Hendricks, K., Singhal, V., 1997. Does implementing an effective TQM program actually improve operating performance? Empirical evidence from firms that have won quality awards. Management Science 43 (9), 1258-1274.

Hjorth-Anderson, C., 1984. The concept of quality and the efficiency of markets for consumer products. Journal of Consumer Research 11, 708-718.

Instone, F., Dale, B., 1989. A case study of the typical issues involved in quality improvement. International Journal of Operations and Production Management 9 (1), 15-26.

Juran, J., 1988. Quality Control Handbook. McGraw-Hill, New York.

Karmarkar, U., Pitbladdo, R., 1997. Quality, class, and competition. Management Science 43 (1), 27-39.

Kekre, S., Murthi B., Srinivasan, 1995. Operating decisions, supplier availability and quality: an empirical study. Journal of Operations Management 12, 387-396.

Kolesar, P., 1995. Partial quality management: an essay. Production and Operations Management 4 (3), 195-200. 
Lawler, E., 1994. Total quality management and employee involvement: are they compatible? Academy of Management Executive 8 (1), 68-76.

Maani, K., 1989. Productivity and profitability through qualitymyth and reality. International Journal of Quality and Reliability Management 6 (3), 11-23.

Maani, K., Putterill, M., Sluti, D., 1994. Empirical analysis of quality improvement in manufacturing. International Journal of Quality and Reliability Management 11 (7), 19-37.

MacDonald, J., 1993. TQM: Does it Always Work? TQM Practitioner Series. Technical Communications (Publishing) Ltd.

Madu, C., Kuei, C., Lin, C., 1995. A comparative analysis of quality practice in manufacturing firms in the US and Taiwan. Decision Sciences 26 (5), 621-636.

Mann, R., Kehoe, D., 1995. Factors affecting the implementation and success of TQM. International Journal of Quality and Reliability Management 12 (1), 11-23.

Masterson, S., Olian, J., Schnell, E., 1997. Belief versus practice in management theory: total quality management and agency theory. Advances in the Management of Organisational Quality 2, 169-209.

McDonnell, J., 1992. Three years of total quality management. Journal for Quality and Participation 15 (1), 6-9.

Mohrman, A., Mohrman, S., Ledford, G., Cummings, T., Lawler, E., 1989. Large-Scale Organizational Change. Jossey-Bass, San Francisco.

Munroe-Faure, L., Munroe-Faure, M., 1992. Implementing Total Quality Management, Pitman, London.

Myers, K., Ashkenas, R., 1993. Results-driven quality ... now!. Management Review 82 (3), 40-44.

Oakland, J., Sohal, A., 1987. Production management techniques in UK manufacturing industry: usage and barriers to acceptance. International Journal of Operations and Production Management 7 (1), 8-37.

Papa, F., 1993. Linkage of old and new. Management Review $82(1), 63$.

Parasuraman, A., Zeithaml, V., Berry, L., 1988. SERVQUAL: a multi-item scale for measuring consumer perceptions of service. Journal of Retailing 64 (1), 12-40.

Phillips, L., Chang, D., Buzzell, R., 1983. Product quality, cost position and business performance: a test of some key hypotheses. Journal of Marketing 47, 26-43.

Powell, T., 1995. TQM as competitive advantage: a review and empirical study. Strategic Management Journal 16 (1), 15-37.

Price, M., Chen, E., 1993. Total quality management in a small, high-technology company. California Management Review, 96-117.

Reed, R., Lemak, D., Montgomery, J., 1996. Beyond process: TQM content and firm performance. Academy of Management Review 21 (1), 173-202.

Reeves, V., Bednar, D., 1994. Defining quality: alternatives and implications. Academy of Management Review 19 (3), 419445 .

Reger, R., Gustafson, L., Demarie, S., Mullane, J., 1994. Reframing the organisation: why implementing total quality is easier said than done. Academy of Management Review 19 (3), 565-584.

Rungtusanatham, M., Forza, C., Filippini, R., Anderson, J., 1998. A replication study of a theory of quality management underlying the Deming management method: insights from an Italian context. Journal of Operations Management 17, 77-95.

Samson, D., Terziovski, M., 1999. The relationship between total quality management practices and operational performance. Journal of Operations Management 17 (4), 393-409.

Saraph, J., Benson, P., Schroeder, R., 1989. An instrument for measuring the critical factors of quality management. Decision Sciences 20 (4), 810-829.

Sitkin, S., Sutcliffe, K., Schroeder, R., 1994. Distinguishing control from learning in total quality management: a contingency perspective. Academy of Management Review 19 (3), 537-564.

Sluti, D., Maani, K., Putterill, M., 1995. Empirical analysis of quality improvement in manufacturing: survey instrument development and preliminary results. Asia Pacific Journal of Quality Management 4 (1), 47-72.

Sousa, R., 2000. Quality Management Practice: Universal or Context Dependent? An Empirical Investigation, Unpublished $\mathrm{Ph} . \mathrm{D}$. Thesis. London Business School, University of London, UK.

Sousa, R., Voss, C., 2002. Quality management: universal or context dependent? Production and Operations Management. Special Issue on Quality Management.

Spencer, B., 1994. Models of organisation and total quality management: a comparison and critical evaluation. Academy of Management Review 19 (3), 446-471.

Stone-Romero, E., Stone, D., Grewal, D., 1997. Development of a multi-dimensional measure of perceived product quality. Journal of Quality Management 2 (1), 87-111.

Tushman, M., Romanelli, E., 1985. Organizational evolution: a metamorphosis model of convergence and reorganization. In: Cummings, L., Staw, B. (Eds.), Research in Organizational Behavior. JAI Press, Greenwich, CT, pp. 171-222.

Van de Wiele, T., Dale, B., Timmers, J., Bertsch, B., Williams, R., 1993. Total quality management: a state-of-the-art survey of European industry. Total Quality Management 4 (1), 23-38.

Van der Akker, G., 1989. Managing quality across cultures. TQM Magazine, August.

Waldman, D., 1994. The contributions of total quality management to a theory of work performance. Academy of Management Review 19 (3), 510-536.

Watson, J., Korukonda, A., 1995. The TQM jungle: a dialectical analysis. International Journal of Quality and Reliability Management 12 (9), 100-109.

Whalen, M., Rahim, M., 1994. Common barriers to implementation and development of a TQM program. Industrial Management 36 (2), 19-21.

White, G., 1996. A meta-analysis model of manufacturing capabilities. Journal of Operations Management 14, 315-331.

Yusof, S., Aspinwall, E., 2000. TQM implementation issues: review and case study. International Journal of Operations and Production Management 20 (6), 634-655. 